التكنولوجيا التعليمية ودورها في الدمج الأكاديمي للتلاميذ ذوي صعوبات التعلم

Educational technology and its role in the academic integration of pupils with learning difficulties

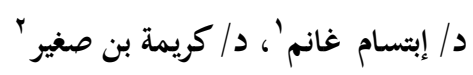

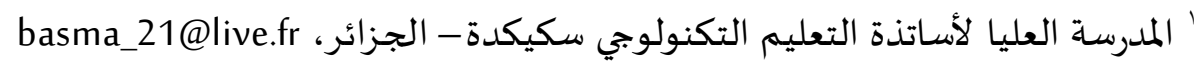

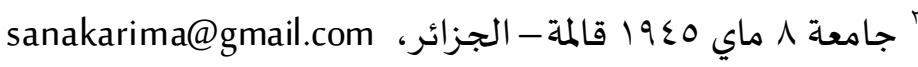
تاريخ القبول: 2021/02/15 تاريخ الاستلام: 2021/01/26

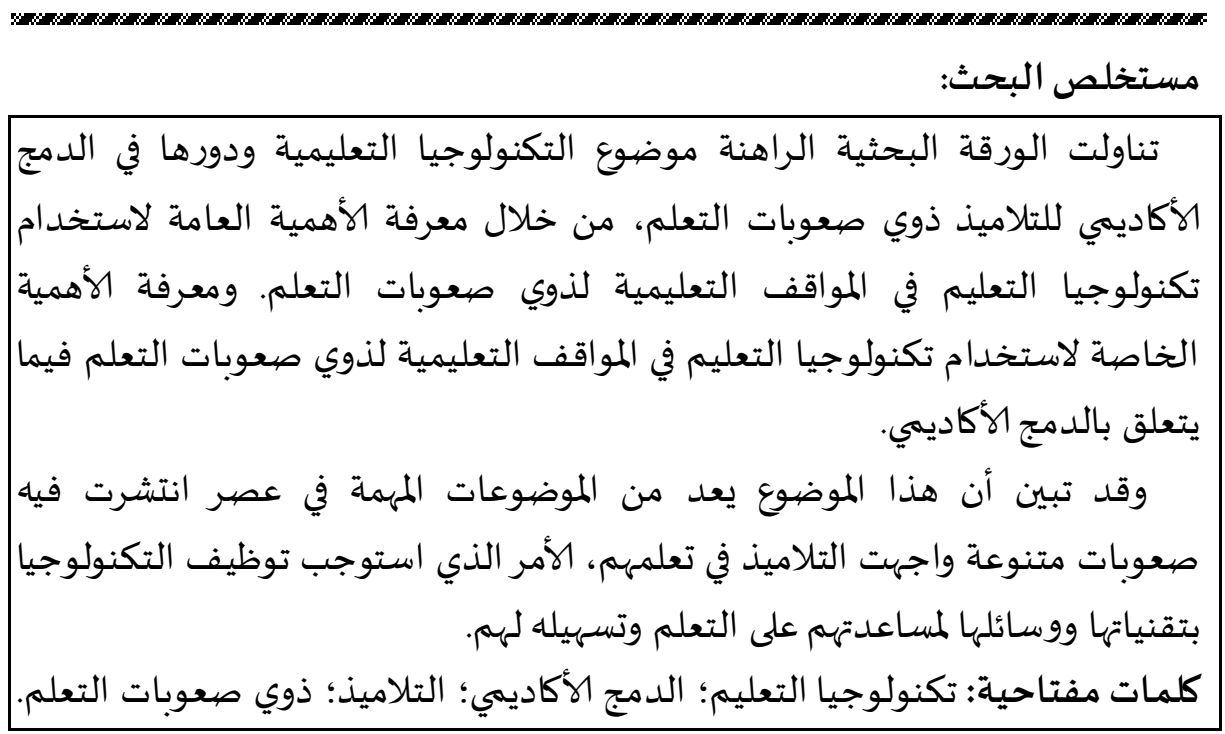




\begin{abstract}
:
The current research paper deals with the subject of educational technology and its role in the academic integration of students with learning difficulties, by identifying the general importance of using educational technology in educational situations for pupils with learning difficulties. As well as recognizing the special importance of using educational technology in educational situations for those who suffer from learning difficulties in relation to academic integration.

It has been proven that this topic is one of the important topics in an era in which students face various difficulties in their learning, which necessitates the use of technology with its techniques and means to help them learn and facilitate it for them.

Keywords: Educational technology; academic integration; pupils; learning difficulties.
\end{abstract}

\title{
مقدمة - مق
}

يعتبر المختصيون والعاملون في مجال التعليم والتربية الخاصة أن موضيوع صعوبات

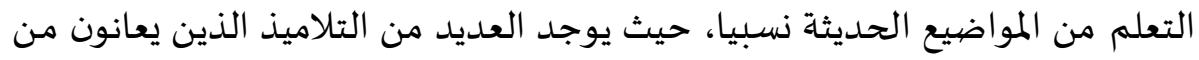

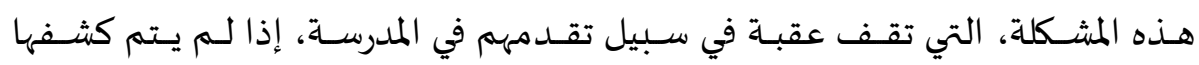

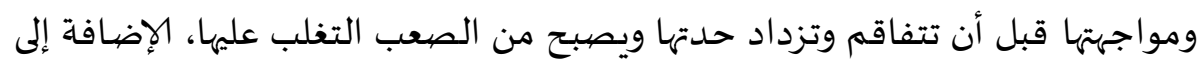

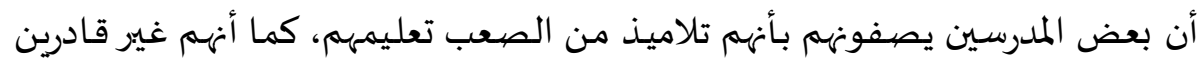

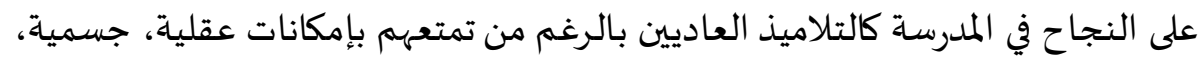
حسية وانفعالية مناسبة.

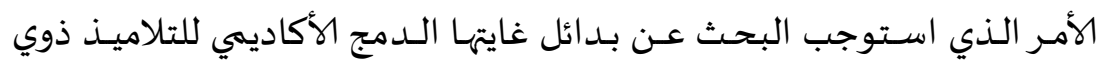

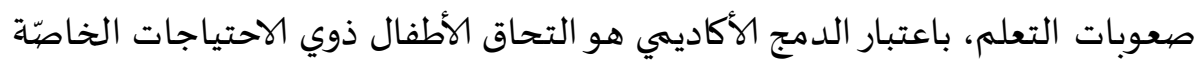

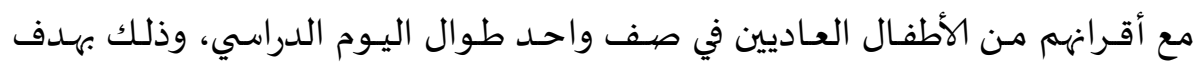
إتاحة الفرصة لهم لتلقي مختلف البرامج التعليمية بالاشتراك مع أقرانهم العاديين.

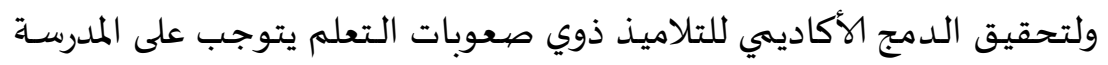

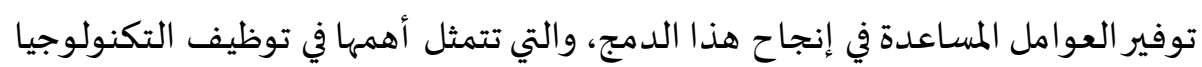


الحديثة التي فرضت نفسها في مختلف المجالات وخاصة المجال التعليهي، حيث أصبح لزاما على المدرسة توظيف التكنولوجيا التعليمية، خصوصيا مع التلاميذ الذيـن لا تسـمح لهم قدراتهم للانخراط الجيد في الأقسام العادية التي يتم فيها تدردس أقرانهم العاديين. و عليـ فإن هذا المسـار هـو الذي سـتتناوله هذه الورقة البحثيـة، من خلال السعي إلى

تحقيق أهداف البحث الآتيـة:

معرفة الأهميـة العامـة لاسـتخدام تكنولوجيـا التعليم في المواقـف التعليميـة

$$
\text { لذوي صعوبات التعلم. }
$$

معرفة الأهميـة الخاصيـة لاستخدام تكنولوجيـا التعليم في المواقف التعليميـة لذوي صعوبات التعلم فيما يتعلق بالدمج الأكاديمي.

$$
1 \text { 1. ا. صعوبات التعلم (المفهوم، الأنواعو والأسباب): }
$$

يوجد أكثر من تعري لصعوبات التعلم وكان العالم كيرك Kirk أول من بدء الجهد عام r797، ثم تضافرت الجهود من قبل المختصين، وعرفت الصعوبات التعليمية التي يواجهها المتعلمون بما يلي: يعرف باتمان Batman الأطفال ذوي صعوبات التعلم، بأنهم أولئك الأطفال الذين يظهرون تناقضا تعليميا بين قدرتهم العلمية العامة ومستوى انجازهم الفعلي، وذلك من خلال ما يظهر لديهم من اضطرابات في عملية التعلم، وان هذه الاضطرابات من المحتمل أن تكون مصحوبة أوغير مصحوبة بخلل ظاهر في الجهاز العصبي المركزي، بينما لا ترجع اضطرابات التعلم لديهم للتخلف العقلي أو الحرمان الثقافي، أو التعليمي،

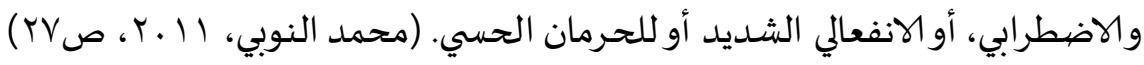
وتعرف الجمعية الأمريكية لصعوبات التعلم الصعوبات التعليمية بأنها صعوبات التعلم الخاصة، وهي حالة مزمنة ذات منشأ عصبي تؤثر في نمو أو تكامل أو استخدام مهارات اللغة اللفظية وغير اللفظية، وتظهر هذه الصعوبات لدى أفراد يتمتعون بلدرجات متوسطة أو عالية من الذكاء، وأجهزة حسية وحركية طبيعية، وتتوفر لديهم فرص التعلم المناسبة، وتختلف آثار هذه الصعوبات على تقدير الفرد لذاته وعلى أنشطته التربوية والاجتماعية والمهنية، وأنشطة الحياة الطبيعية باختلاف رجةة شدة

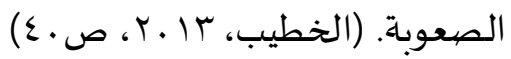


ويعرف لينر صعوبات التعلم بأنه مفهوم يتضيمن بعدين هما:

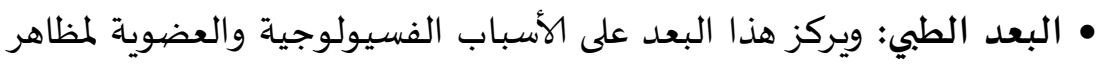

صعوبات التعلم والتي تتمثل في خلل الجهاز العصبي أو التلف الدماغي البسيط.

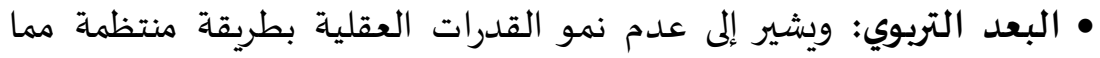

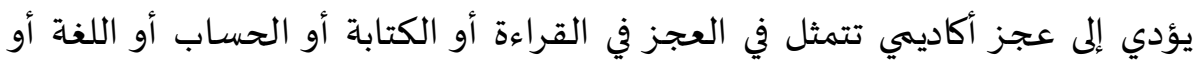

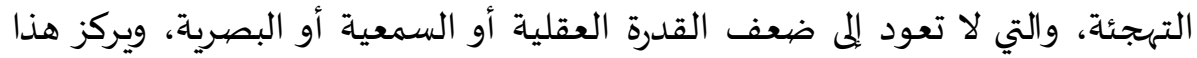

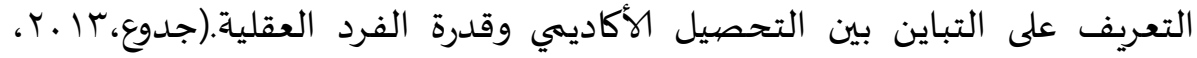

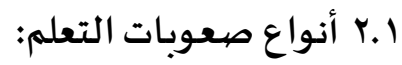
فيما يخص أنواع صعوبات التعلم فتصنف إنوات إلى قسمين أساسيين هما: صعوبات التعلم النمائية: تتعلق بالوظائف الدماغية وبالعمليات العقلية والمعرفية التي يحتاجها الطفل في تحصيله الأكاديمي، وقد يكون السبب في حدوثها اضطرابات تخص الجهاز العصبي

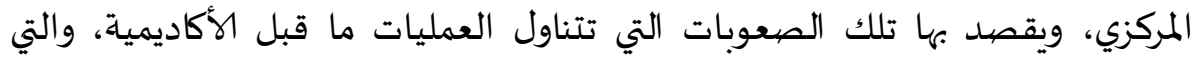

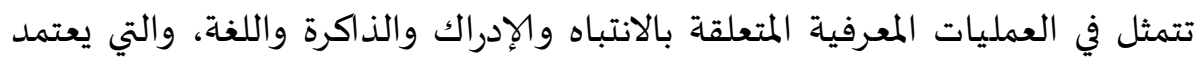

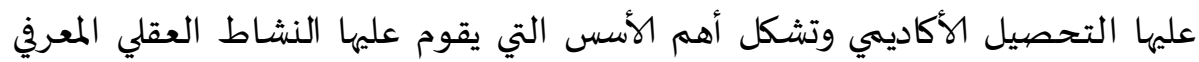
للفرد، ويمكن تقسيم هذه الصعوبات إلى نوعين فرعيين هما:

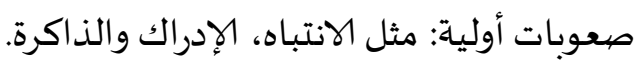

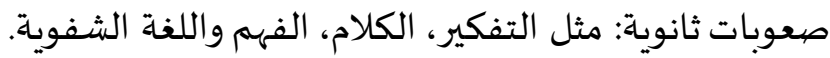

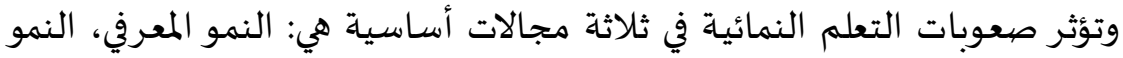

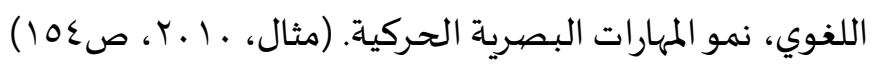
صعوبات التعلم الأكاديمية: يقصيد بها صعوبات الأداء المدرسي المعرفي الأكاديمي، والتي تتمثل في القراءة، الكتابة، التهجئة والحساب، وترتبط هذه الصعوبات إلى حد كبير بصعوبات التعلم

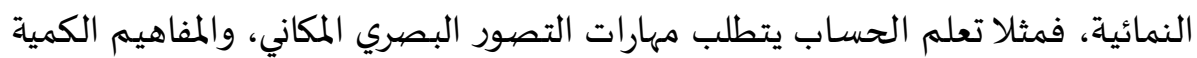
والمعرفة بمدلولات الأعداد وقيمتها وغيرها من المهارات الأخرى. (بني هاني، 10 .ب، 


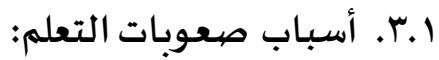

أ- الأسباب العضوية والبيولوجية:

يشير الأطباء إلى الأطفال ذوي صعوبات اليوجيه التعلم على أنهم يعانون من خلل دماغي

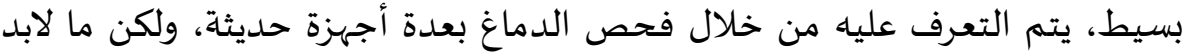

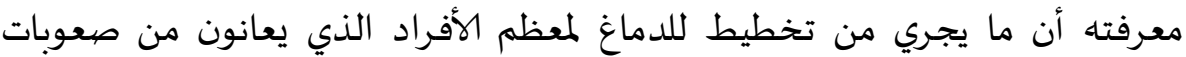

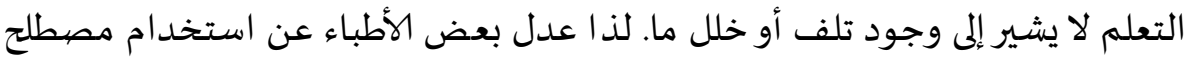

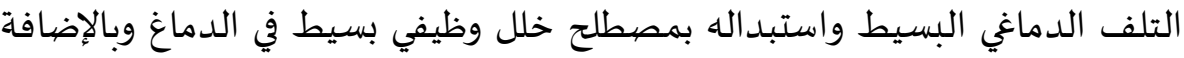

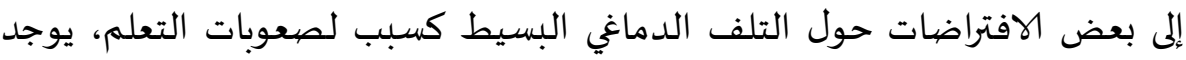

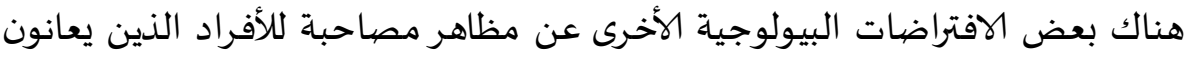

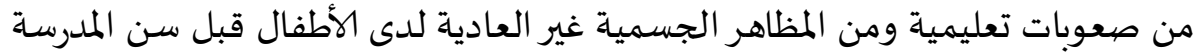
كالتشوهات في شكل الجمجمة، أو انخفاض موقع الأذنين في الجمجمة أو كهربية الشعر.

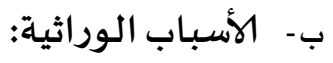

تشير الدراسات إلى أن الوراثة قد تكون من المسببات لبعض حالات صعوبات

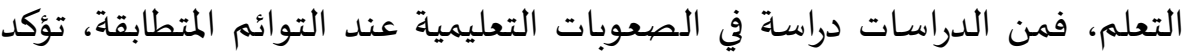
وجود صعوبة في القراءة عند أفراد العينة. كما وأجرى دراسة على التوائم وأشارت

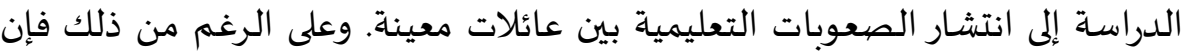

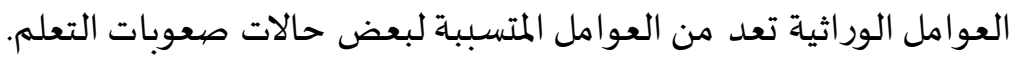

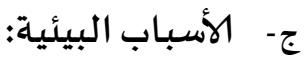
إن العوامل البيئية قد تكون أحد المسببات لصعوبات التعلم فنقص الخبرات التعليمياة، سوء العناية الطبية، وسوء التخذية، والمواد الحافظة والملونة والنكهات

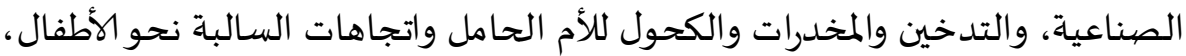

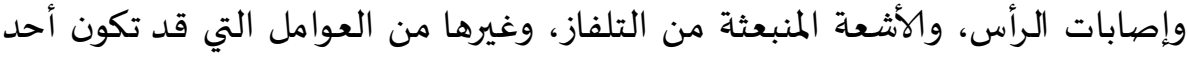

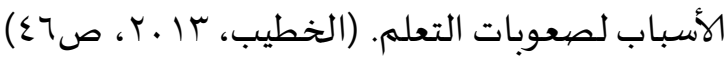
r. التكنولوجيا التعليمية لذوي صعوبات التعلم (المفهوم والأهمية):

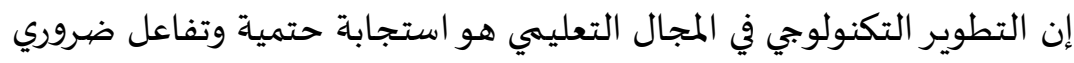

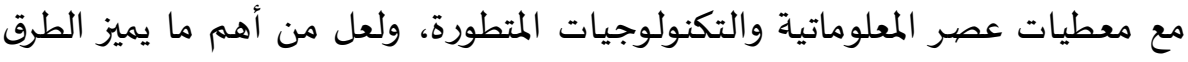

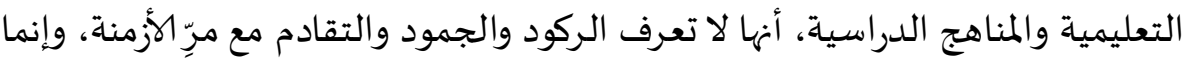


على العكس من ذلك فإنها تتطور متبعة التغيرات الحاصلة على مختلف الأصعدة والمجالات خصوصيا التكنولوجية وبنفس الوتيرة.

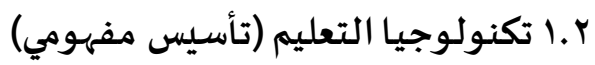

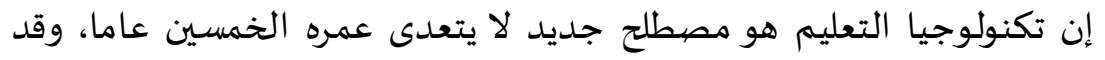

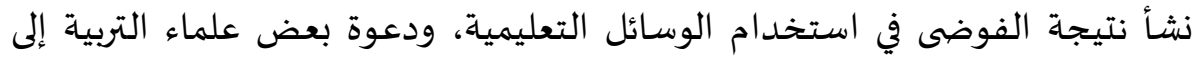

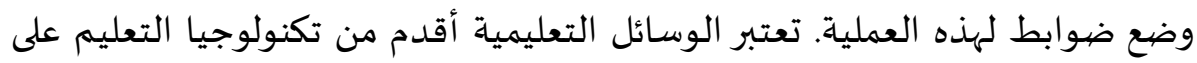

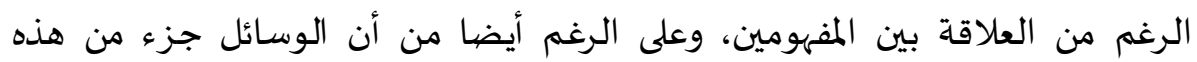
التكنولوجيا وهنا لابد من التفريق بينهما:

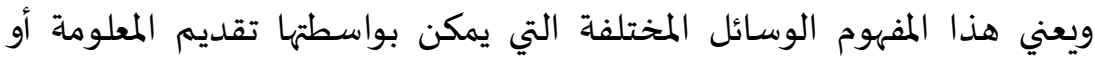

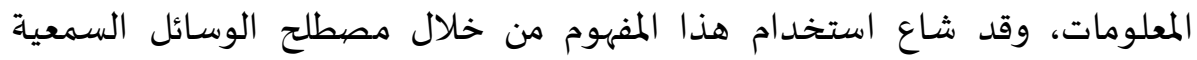

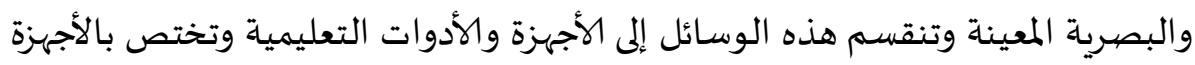

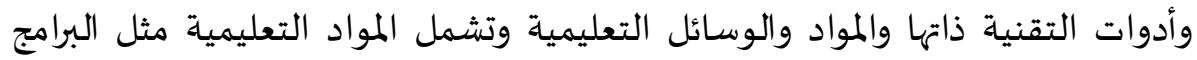

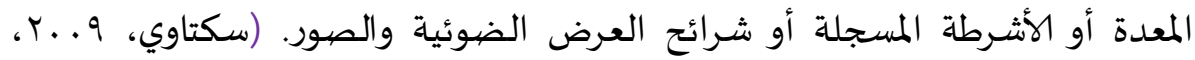

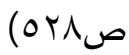

وتعتبر محتوى تعليميا (أدوات تقنية ومواد) وهي ملائمة لموقف تعليمي تعلمي

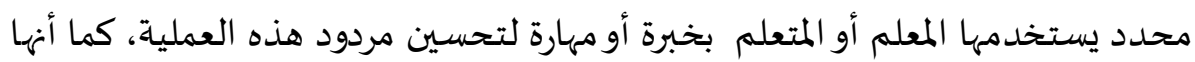

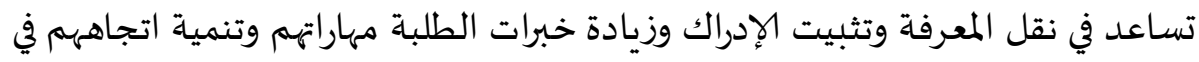

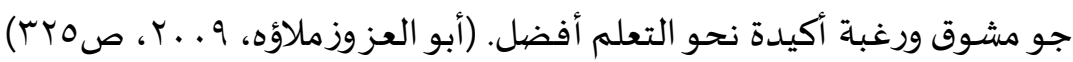

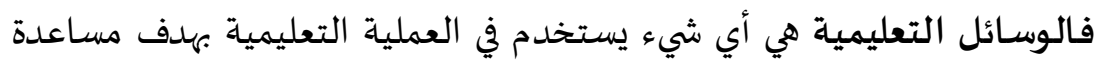

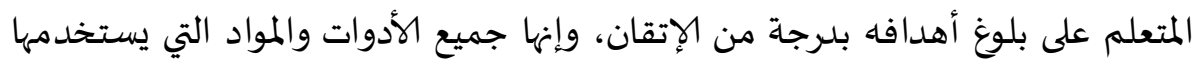

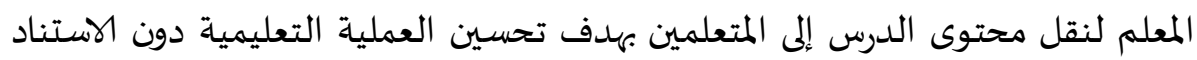
إلى الألفاظ المجردة فقط.

أما تكنولوجيا التعليم فهي أشمل من ذلك، حيث تفيد القواميس الانجليزية بأن

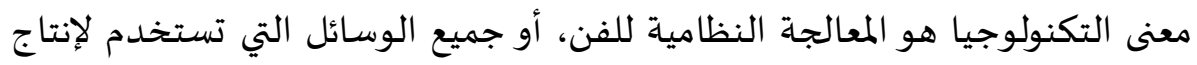

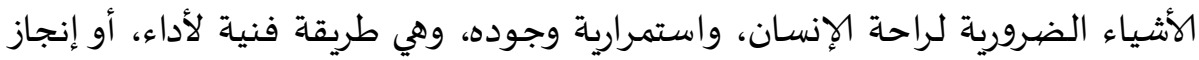

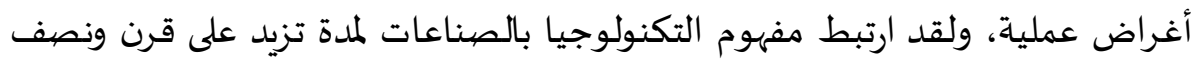

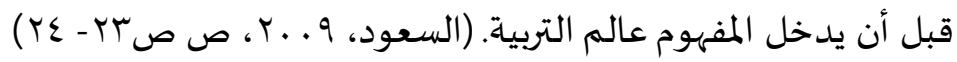


تعد تكنولوجيا التعليم مجموع الموارد السمعية البصرية المستعملة في التعليم كالصور والأفلام وأدوات التسجيل والراديو و التلفزة، تشير إلى منهاجية التعليم كالتعليم المبرمج. هي اتجاه فكري وعملي تطور وفق تيارين: تطبيق نظريات التعلم في الممارسة البيداغوجية وإدماج مقاربات لتنظيم المعرفة وتحديد الأهداف.(الفاربي وآخرون،

ع 199، ص00)

فهي بذلك طريقة نظامية منهجية تأخذ بعين الاعتبار جميع المصادر البشرية واحتياجات المتعلمين ومستوياتهم، والأهداف التربوية.

r.Y أهمية استخدام التكنولوجيا التعليمية في المواقف التعليمية:

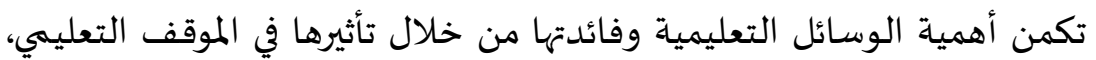

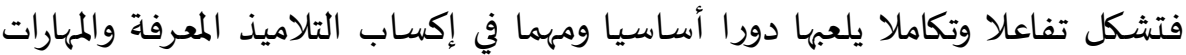

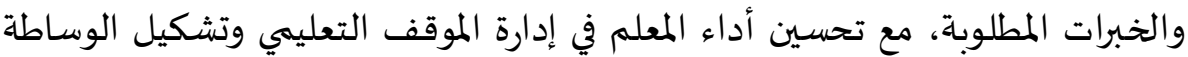

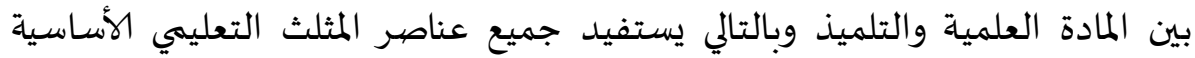

" يمكن استخدام الوسيلة التعليمية مرات عدة، ومن أكثر من معلم، وهذا يقلل

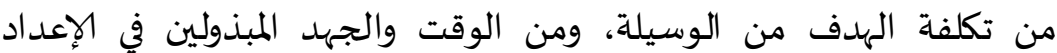
للموقف التعليمي.

- تغير دوره من ناقل للمعلومات وملقن إلى وسيط ومخطط ومنفذ. " يمكن عن طريق الوسائل التعليمية تنويع أساليب التعزيز.

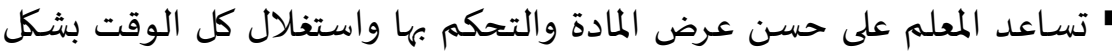
أفضل.

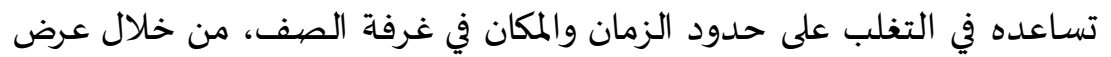

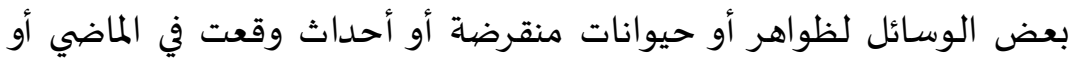

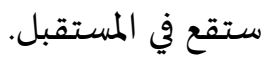
تساعد المعلم لإثارة الدافعية لدى التلاميذ عبر القيام بنشاطات لحل المشكلات. " رفع استعدادات وكفاية المعلم المهنية. 


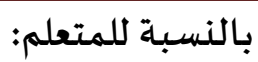

• تشجيع المتعلمين على المشاركة والتفاعل مع المواقف الصفية المختلفة.

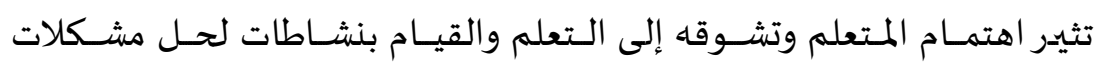
واكتشاف حقائق. تقوية العلاقة بين المعلم والمتعلم، وبين المتعلمين أنفسهم، خاصية عند استعملها بكفاية. إتاحة فرص للتنويع والتجديد المرغوبة، وبالتالي تساهم في علاج مشكلة الفروق الفردية. القضيـاء على الـروتين والملل، فـالمتعلمين يكونـون أكثثر اسـتعدادا لتقبـل المـادة التعليمية.

$$
\begin{aligned}
& \text { تنمي في المتعلمين حب الاستطلاع واكتشاف الاتجاهات المرغوب فيها. }
\end{aligned}
$$

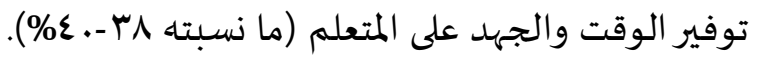

تعالج اللفظية والتجريد، وتزيد ثروة التلاميذ من الألفاظ. تجعل الخبرات التعليمية أكثر فعالية، وأبقى أثرا، وأقل احتمالا للنسيان.

بالنسبة للمادة العلمية:

تساعد على إبقاء المعلومات حية وذات صيورة واضحة في ذهن المتعلم.

$$
\text { تقريب المواضيع إلى عروض وحالات حقيقية واقعية. }
$$

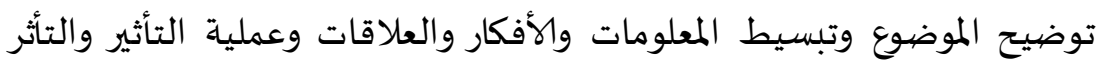

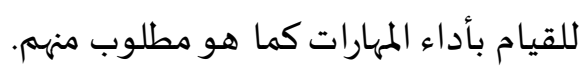

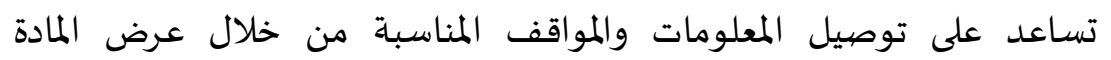

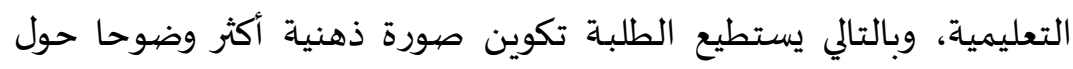

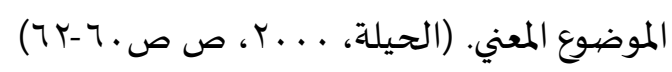

r.r.r تكنولوجيا التعليم لذوي صعوبات التعلم، أنواعها وأهميتها:

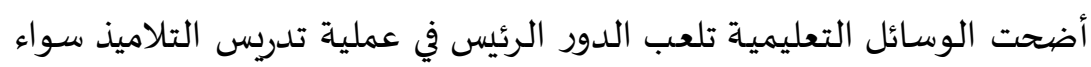

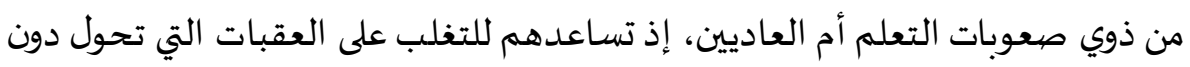
استقلالهم، وتيسر تواصلهم الاجتماعي وترفع قدرتهم في تطبيق مهارات الحياة اليومية. 


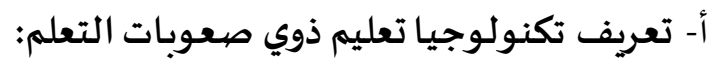

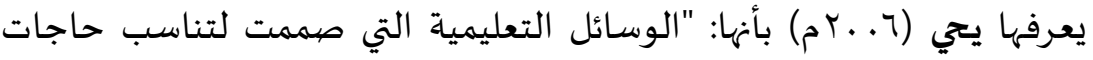

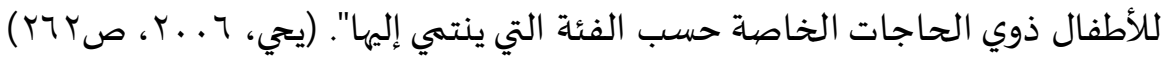

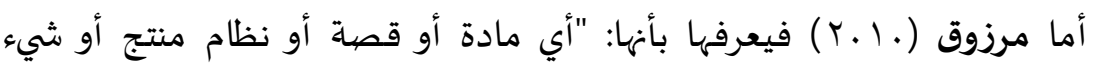

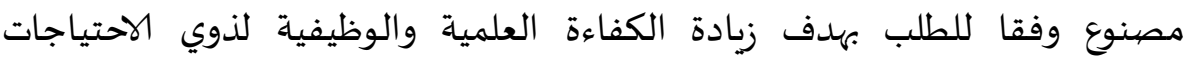

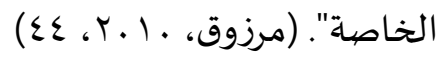

ب- أنواع تقنيات التعليم لذوي صعوبات التعات التعلم:

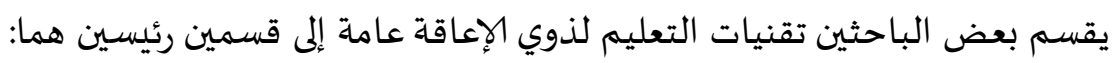

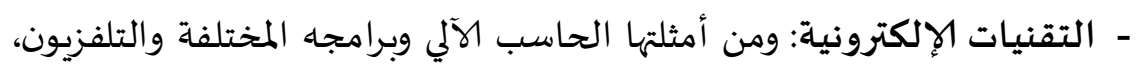

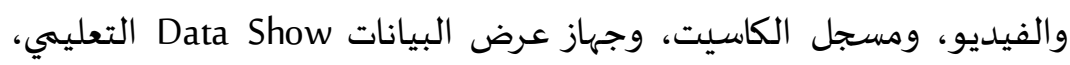
والآلة الحاسبة وغيرها من الأجهزة الكهربائية والإلكترونية.

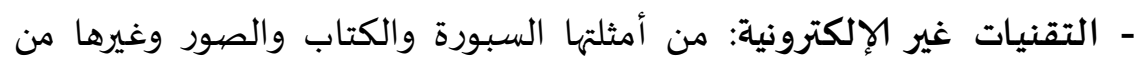
الوسائل غير الكهربائية، أو الإلكترونية.

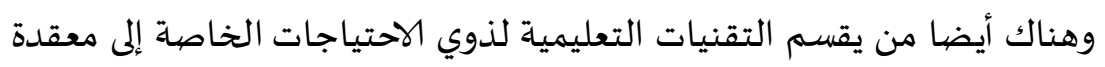

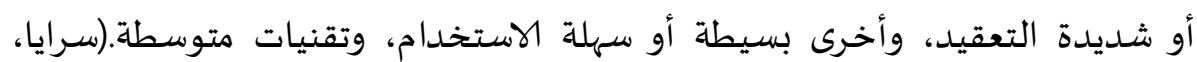

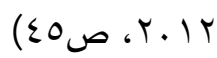
تكنولوجيا التعليم وأهميتها لتعلم ذوي صعوبات التعلم:

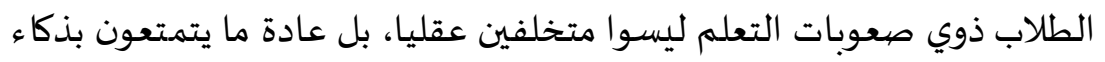

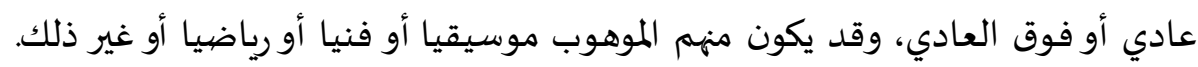

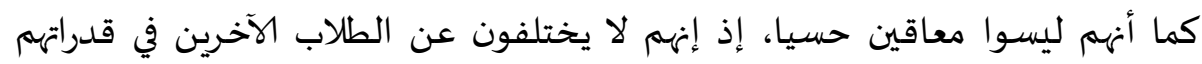

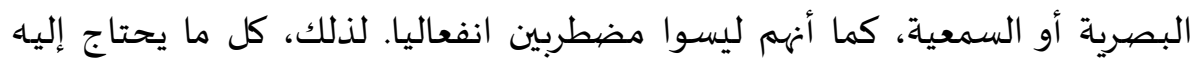

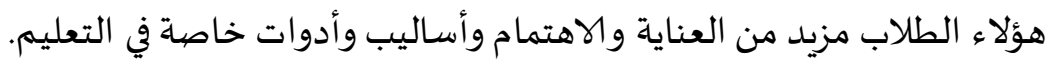

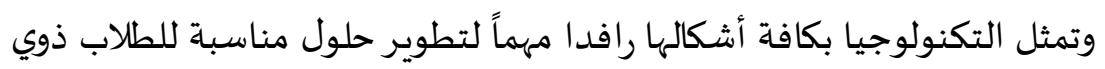

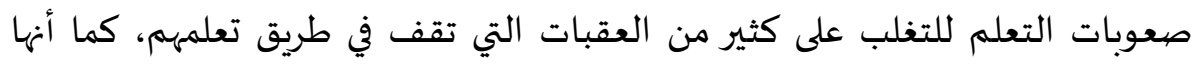

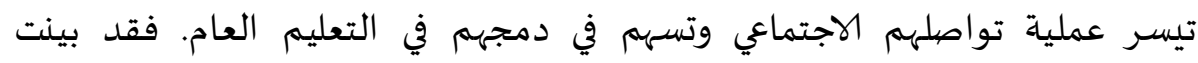

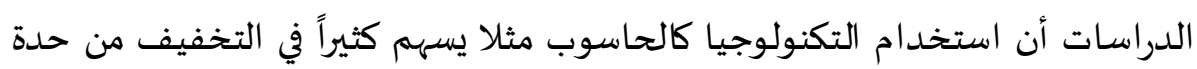




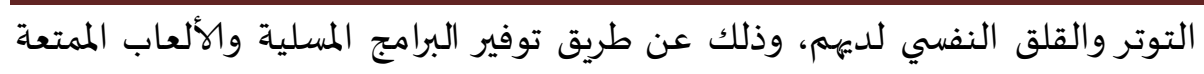
التي تدخل البهجة والسرور إلى نفوسهم.

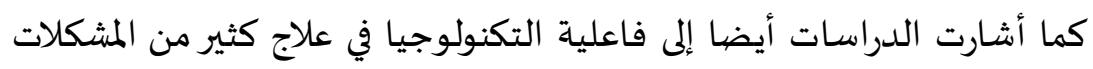

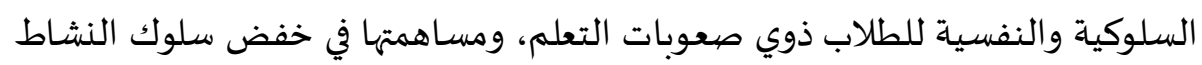
الزائد وتحسين بعض السلوكيات المصاحبة له كتشتت الانتباه والاندفاعية وفرط

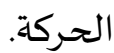

وتلعب التكنولوجيا دورا مهما في تنمية مهارات الإدراك البصري لدى الطلاب

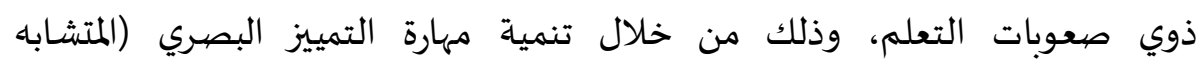

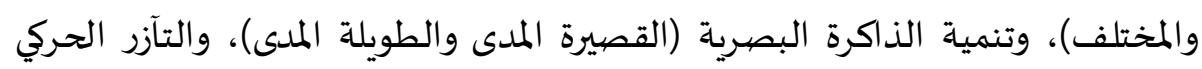

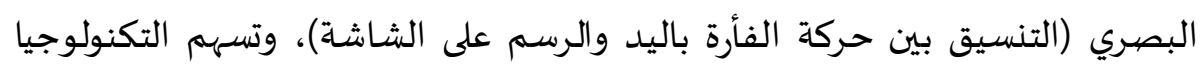

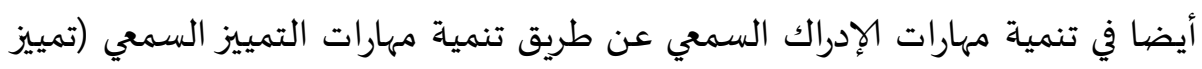

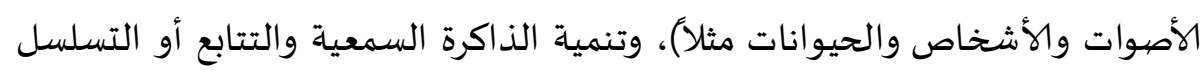

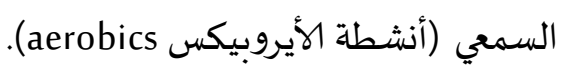

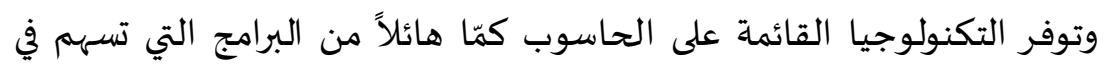

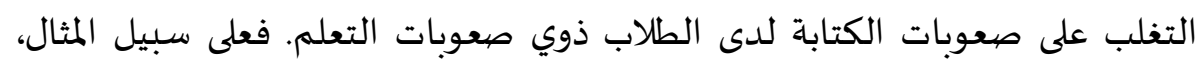

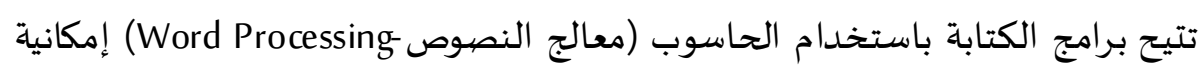

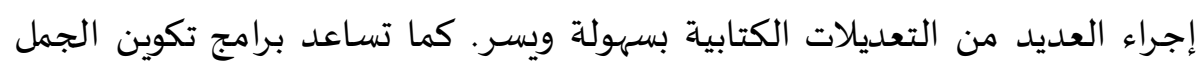
(Sentence Generation)

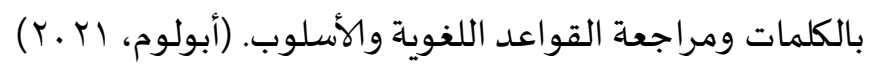

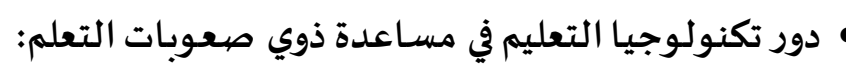

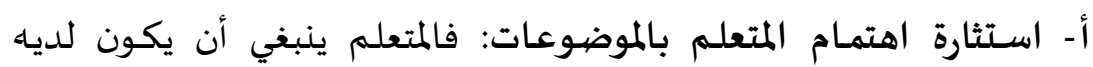

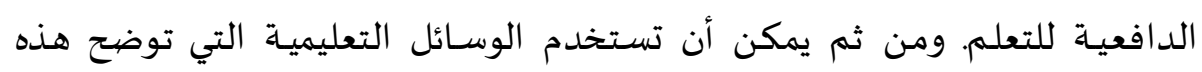

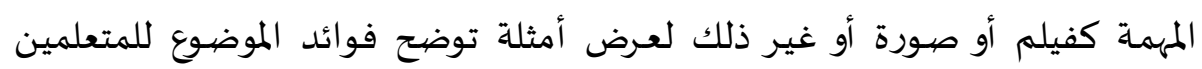

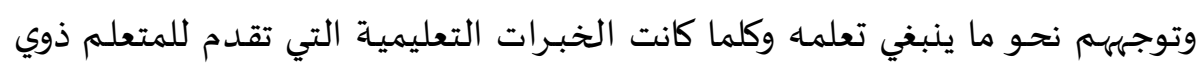

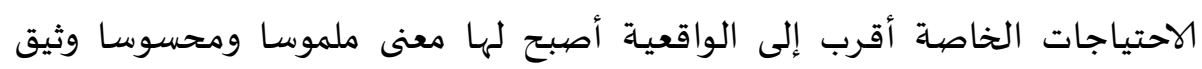
الصلة بالأهداف التي يسعى إلى تحقيقها. 
ب- التغلب على مشكلة اللفظيـة: قـد تتضهمن بعض المواقف التعليميـة تقديم بعض المفاهيم العلميـة للتلميـذ بعبـارات أو ألفاظ يصعب على التلميـ ذي الإعاقة البصرية أو السمعية أو الذهنيـة فهمها. ولكن باستخدام الوسبيلة المناسبة لتوضيح أو أو تبسـيط هـا المفهوم بطريقـة ماديـة.

ت - توسـيع مجالات الخبـرة وتنوعها: فاسـتخدام الوسـائل التعليميـة يتيح للمتعلهم الفرصـة للمشـاهدة والاستماع والممارسـة والتأمل والتفكيـر، مما يعمل على

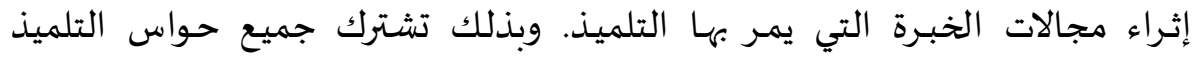
(السليمةة) في عمليات التعلم، مما يترتب عليـه أن يصبـح التعلهم باقي الأثر. ث- تهيئة الخبرات التعليميـة المباشـرة: تتصل بعض الموضوعات الدراسية بالبيئات الخارجية والتي قد يصعب على الأفراد ذوي الإعاقة الإلمام بها بطريقـة كلية نتيجــة لما يفرضـاه النقص الناتـج عن قصيور حاسـة مـا. فالوسـائل التعليميـة تلعب دورا في تهيئـة الفرص للتلاميذ لاكتساب الخبرات المباشـرة عن طريق الأنشطة المختلفة التي تتخلل تدرسس هـذه الموضيوعات سـواء في الرحلات أو الزيارات الميدانيـة أو مشاهدة النماذ ج. ج- إتاحسة الفرصـة لذوي الإعاقات للتعلم من خـال الخبـرات البديلة: هناك مواقف وظروف يسـتحيل أو يصعب على الإنسـان أن يتعلم بالخبـرات الحقيقيـة

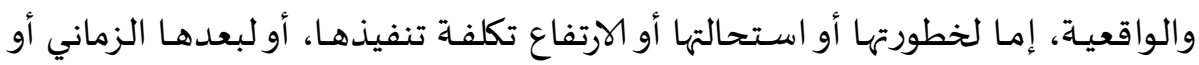
المكاني، أو لصغـر أوكبر حجمهـا. ح- مقابلة الفروق الفردية بين التلاميذ: فلكل إعاقة خصائصها واحتياجاتها التعليميـة التي تختلف عن بقية الإعاقات بل هناك درجات متفاوتة في مستوى القصور للإعاقة نفسها فعلى سبيل المثال توجد درجات متفاوتة من فقدان حاسـة البصر أو السسمع أو الإعاقة الذهنيـة وهكذا. خ- إتاحسة فرص التعلم الذاتي والمستمر: فهؤلاء الأفراد حتى بعد حصولههم على مؤهلات دراسـية هم في حاجـة إلى اكتساب المعارف والمهارات التي تفرضهـا طبيعـة

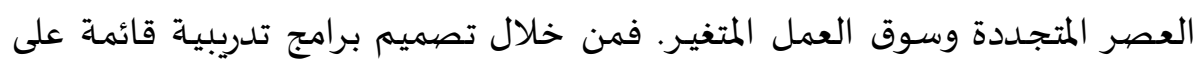
استخدام الوسـائل التعليميـة المختلفة، أمكن مسـاعدة ذوي الإعاقات من تعليم

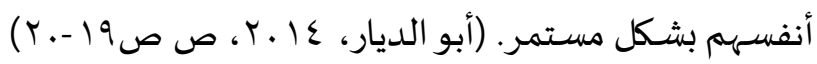


r. الدمج (ماهيته، أشكاله، أهميته، اتجاهاته)

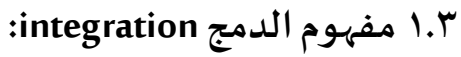
ظهر مصطلح الدمج "integration" بعد المقال الذي نشره لويد دون

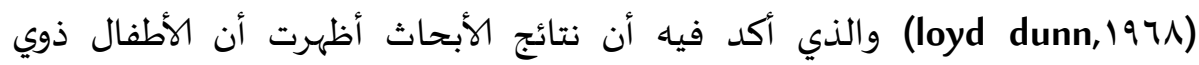

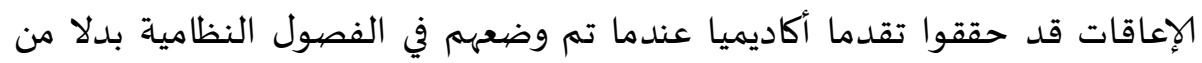

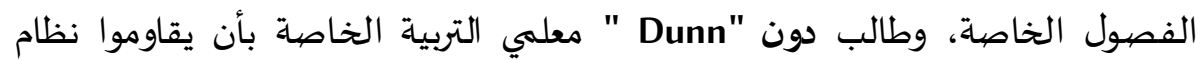
الفصول الخاصة التي تصيب بمشاعر الخزي والشعور بالنقص. (مصطفى، وعبد

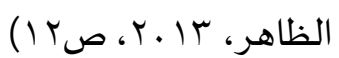
ويرى كوفمان "kauffman" أن الدمج أحد الاتجاهات الحديثة في التربية

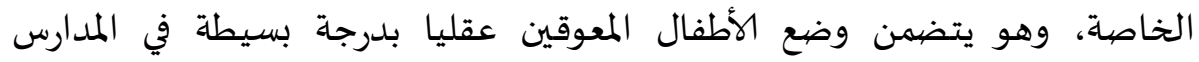

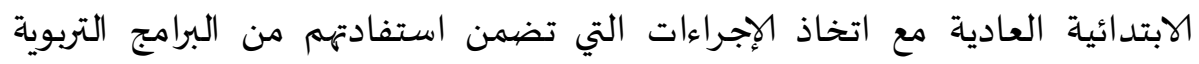

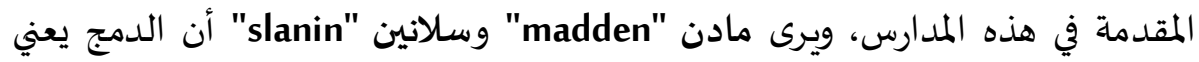

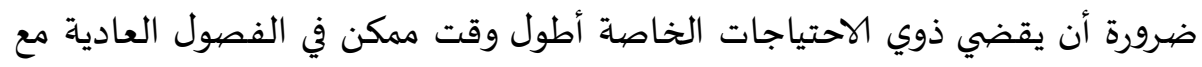

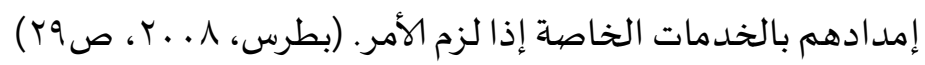
وهناك جماعة من المختصين اختاروا مصطلح التكامل للتعبير عن عملية تعليم

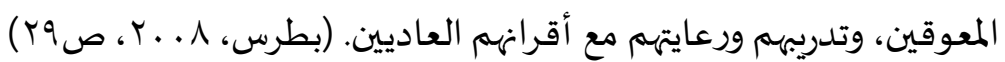

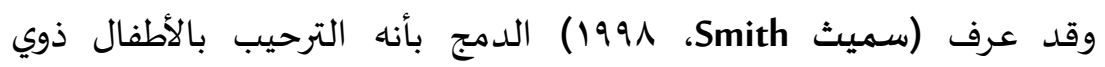

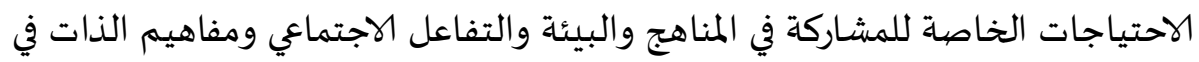

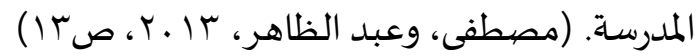
وقد وضعت وارنك (warnok 1978) ثلاثة أشكال أساسية للدمج: (الطلافحة، وعابل

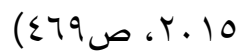

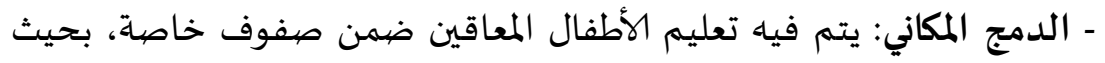
تشترك المدرسة الخاصة مع المدرسة العادية في البناء المدرسي.

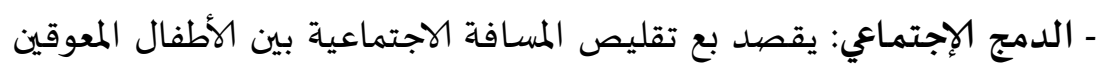

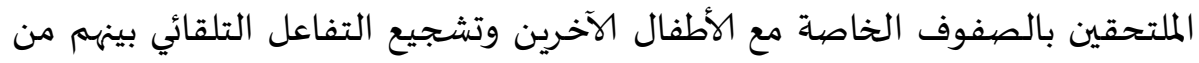

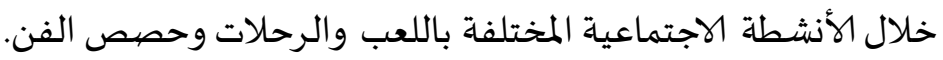


- الدمج الوظيفي: ويقصد به دمج ذوي الاحتياجات الخاصاة في المدارس العادية

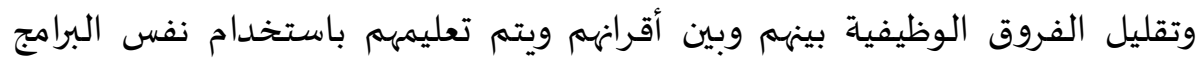

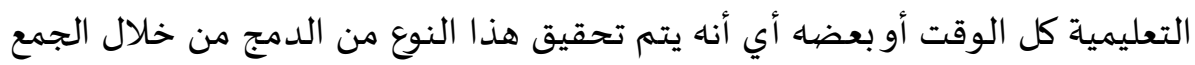

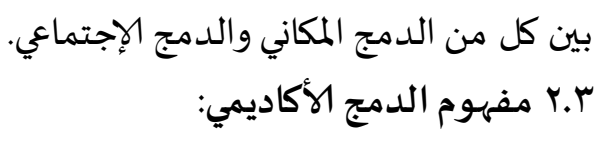

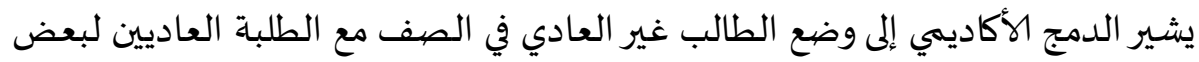

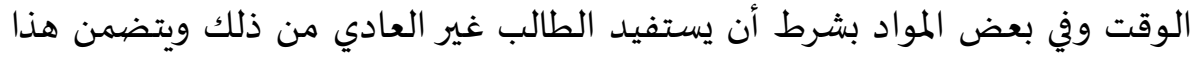

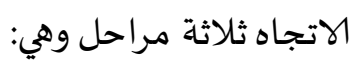

المرحلة الأولى: مرحلة التجانس بين الطلبة العاديين والطلبة ذوي الاحتياجات الترات الخاصة.

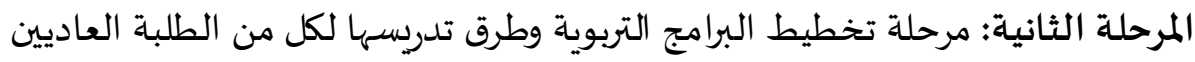

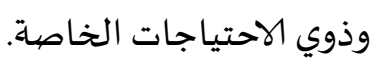

المرحلة الثالثة: مرحلة تحديد المسؤوليات الملقاة على عاتق أطراف العملية التعليمية.

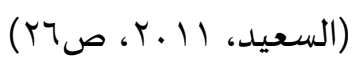

وهناك ثلاثة اتجاهات رئيسية نحو سياسة الدمج يمكن الإشارة إلها على النحو

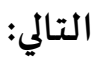
أ- الاتجاه الأول: يعارض أصحاب هذا الاتجاه بشدة فكرة الدمج، ويرون أن تعليم

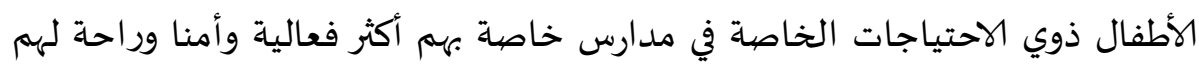

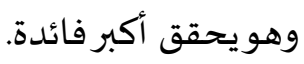
ب-الاتجاه الثاني: يؤدي أصحاب هذا الاتجاه فكرة الدمج لما لذانلك من أثر في تعديل

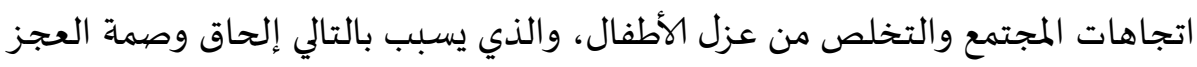

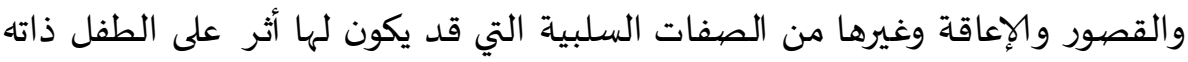

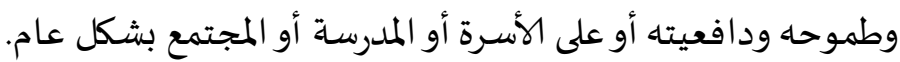

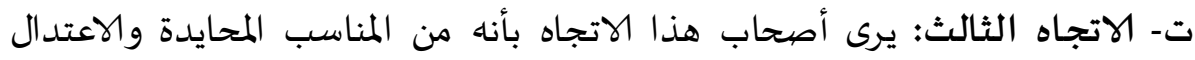

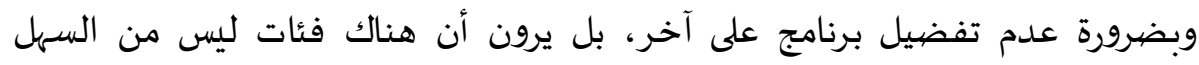

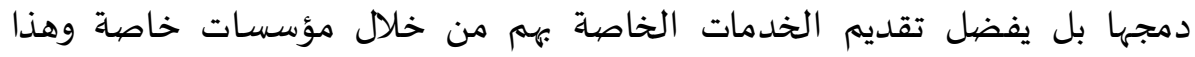
الاتجاه يؤيد دمج الأطفال ذوي الإعاقات البسيطة أو المتوسطة في المدارس العادية 
ويعارض فكرة دمج الأطفال ذوي الإعاقات الشديدة جدا (الاعتمادية) ومتعددي

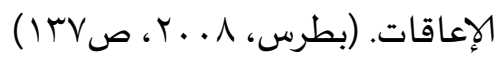

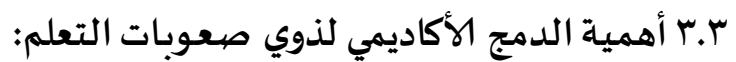
يعتبر التلاميذ ذوي صعوبات التعلم من ذوي الاحتياجات الخاصة الذين الذين

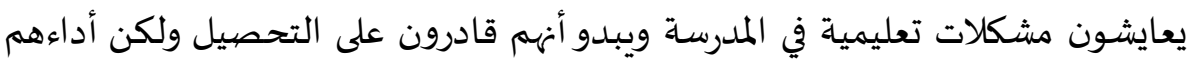

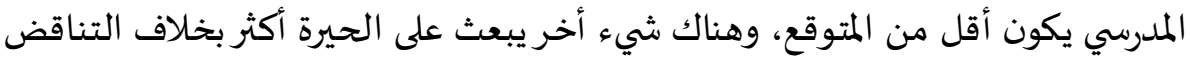

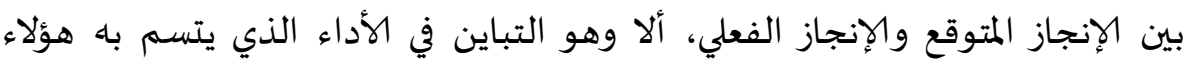

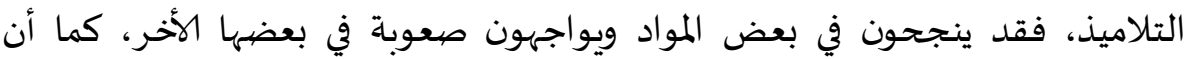

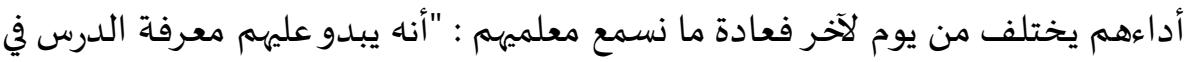

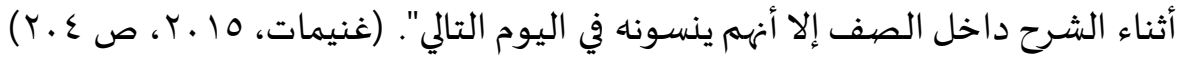

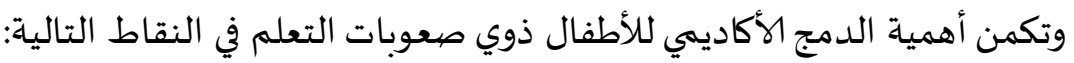

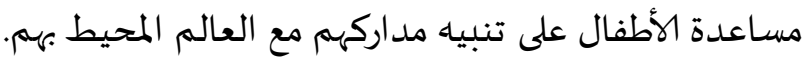

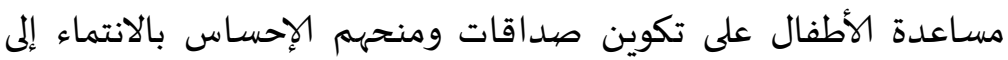
الجماعة. تعليم الأطفال الأنشطة التي تساعدهم على القيام بدورهم في الأسرة والمجتمع ليكونوا أعضاء فاعلين. تنمية ما لدى الأطفال من قدرات وإمكانيات ومواهب ومساءعلئ ومساعدتهم على تعويض العجز. تعليم الأطفال الالتزام بقواعد النظام وتحمل المسؤولية. تعليم الأطفال كيفية التعامل والانسجام مع الآخرين.

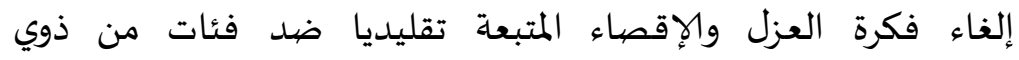
الاحتياجات الخاصة وتغيير نظرة المجتمع السلبية اتجاههم. (بطرس، ولإهرة

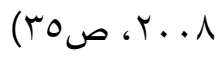

r.ع أهمية استخدام تكنولوجيا التعليم في دمج ذوي صعوبات التعلم: تؤكد العديد من الدراسات فعالية استخدام التقنيات التكنولوجية بشتئى

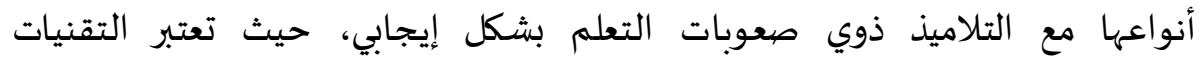

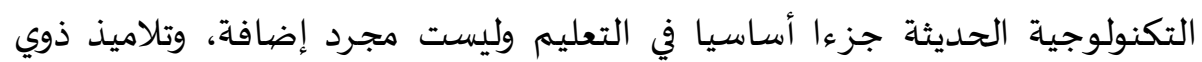


الاحتياجات الخاصية جزء من هذه المنظومة التي تعمل على تسخير التقنيات التعليمية في تربيتهم، حيث تساهم هذه التقنيات في تحقيق العديد من أهداف التربية الخاصية

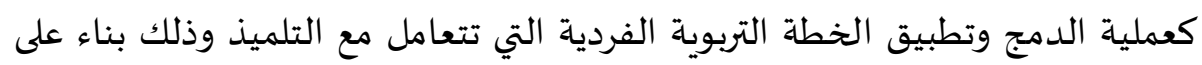

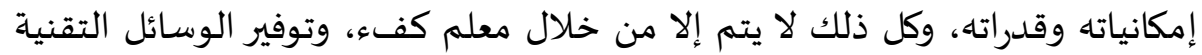

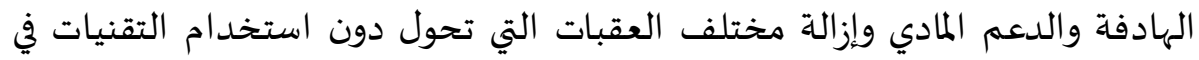

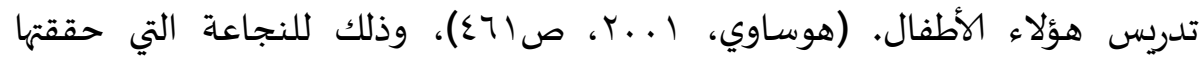

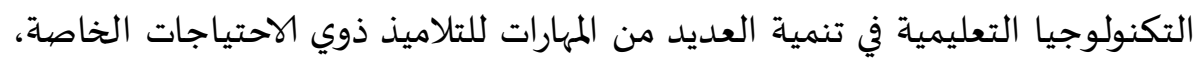
فمثلانجد:

دراسـة باركر (Barker 2003)، التي هدفت إلى تقييم خدمات غرف مصادر التعلم التكنولوجية التي تقدم للطلاب ذوي صعوبات التعلم، وتم إجراء تقييم للخدمات التعليمية التكنولوجية التي تقدمها هذه الغرف باستخدام تكنولوجيا المعلومات والاتصالات في تعليم ذوي صعوبات التعلم، وكانت مشاركة الطلاب إيجابية

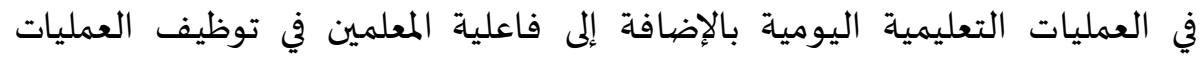

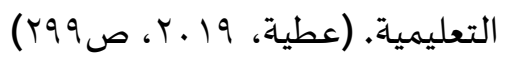

ونجد أيضا دراسة مكارثر وآخرون (Macarthur et al.,1990)، وفيها تم تقييم نموذج مقترح لتعليم الكتابة يجمع بين مدخل العملية وتعليم الطلاب إستراتيجية الكتابة، لكي يجعلها مهمة ذات معنى بالنسبة للطلاب، وقد استخدمت هذه هذه الدراسة عينة قوامها با || طالب من طلاب المرحلة الابتدائية من ذوي صعوبات التعلم، ودلت فئل

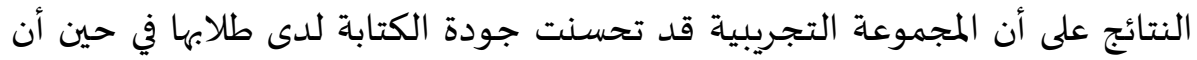
ذلك لم يتحقق للمجموعة الضيابطة. كما بينت دراسة ماكرثر وباربرا (Macarthur, Stoddard barbara,199M)، والتي تعرضت لتقييم فاعلية مدخل لتحسين مهارات المراجعة، وهو يعتمد على التكامل

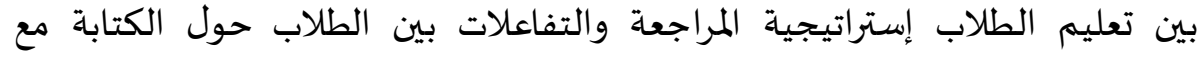

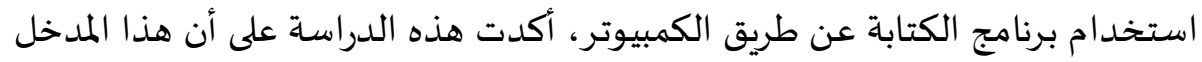

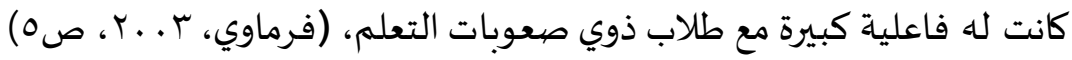

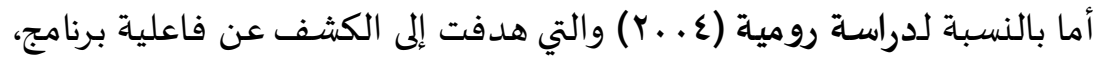
يعتمد تكنولوجيا الحاسب لعلاج صعوبات تعلم الرياضيات لدى طلبة صف روفيه الرابع 
الأساسي بمحافظة شمال غزة، ولتحقيق هدف الدراسة استخدمت الدراسة المنهجين

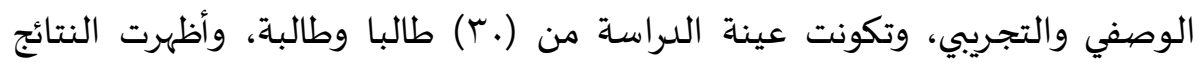
فاعلية البرنامج المحسوب لعلاج صعوبات تعلم الرياضيات لدى طلبة الصفي الرئ الرابع

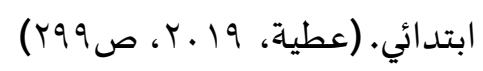

من كل ما سبق التطرق إليه في فحوى هذه الدراسات السابقة يمكن أن

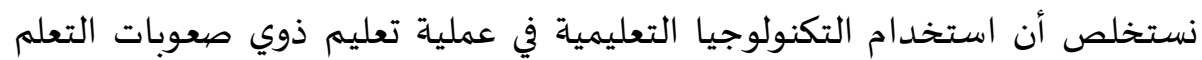

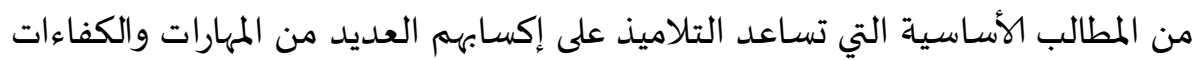

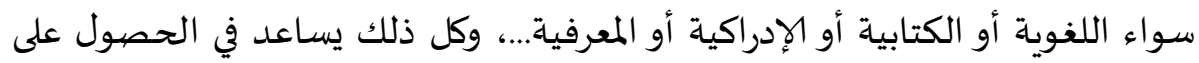

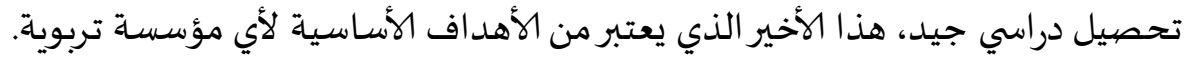

خاتمة تحميل

لقـــ فرضـت التكنولوجيـا الحديثـة نفسـها في المجــال التعليمي لجميـع فئـات

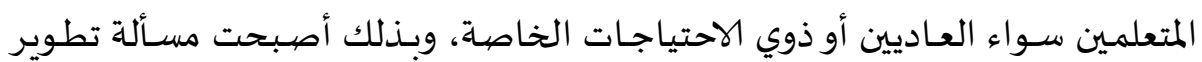

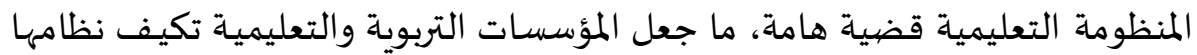

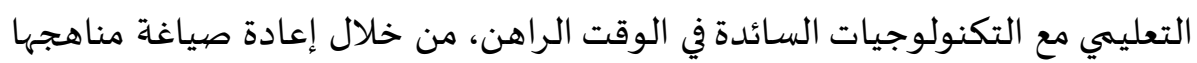

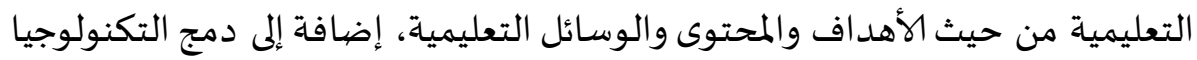

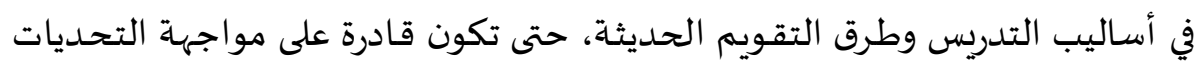

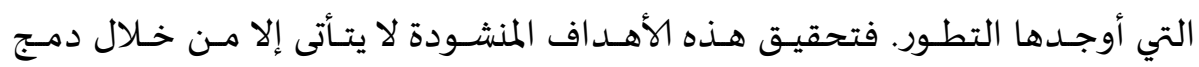

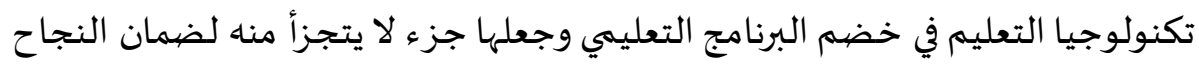

$$
\text { وإنتاج المخرجات التعليمية ذات الكفاءة. }
$$

وهو ما يتوافق مع ما تم استعراضه في هذا البحث من الأهمية الكبيرة التي

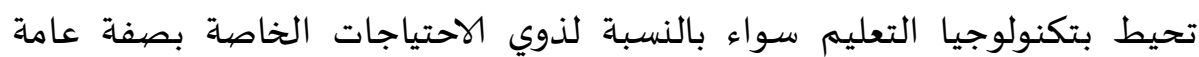
وبالنسبة لذوي صعوبات التعلم بصفة خاصية، حيث استوجب الأمر من المختصين

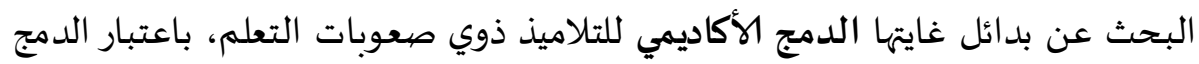

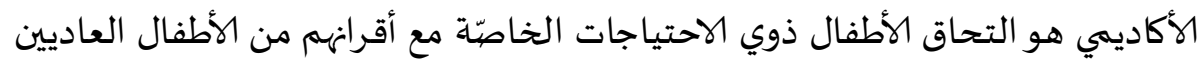

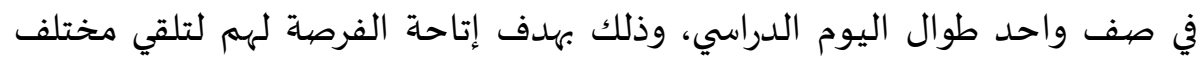

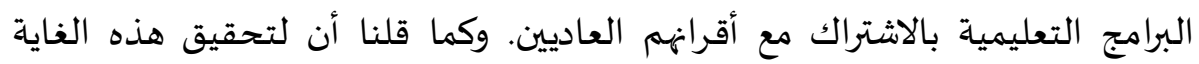
للتلاميذ (الدمج الأكاديمي) ذوي صعوبات التعلم يتوجب على المدرسة توفير العوامل 


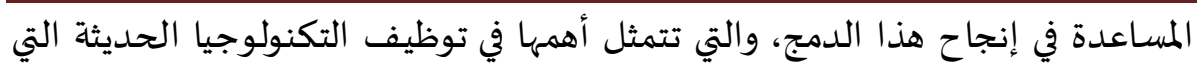

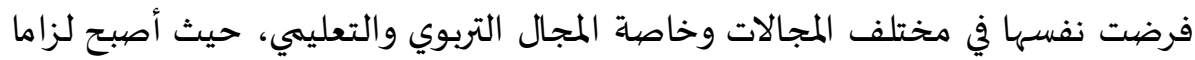

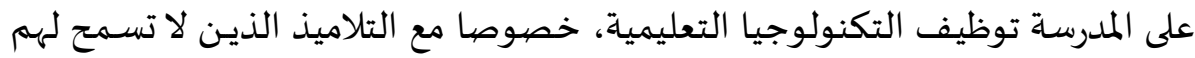

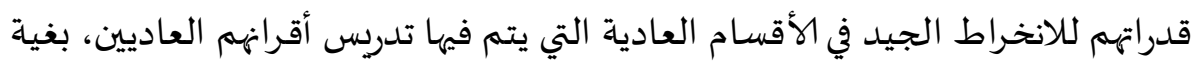

تحسين التحصيل الدراسي لديهم.

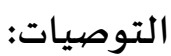

لا يستلزم على كل معلم أن يكون على دراية بمختلف الوسائل التعليمية التي

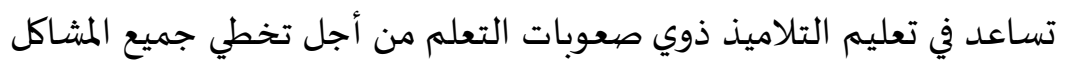

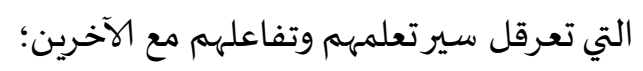

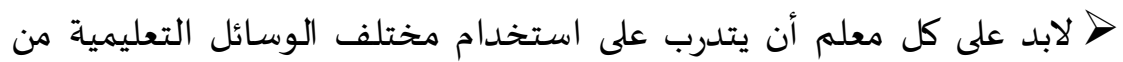

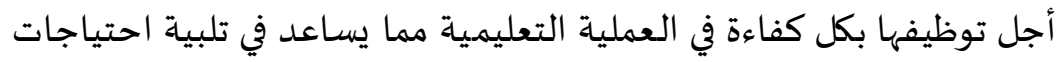

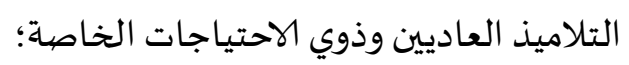

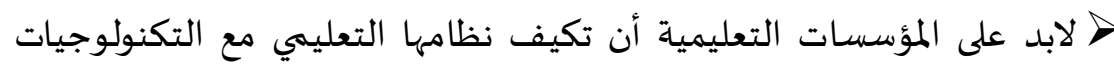

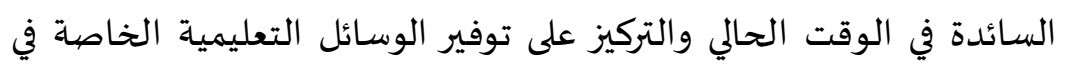

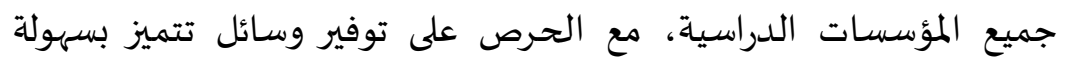

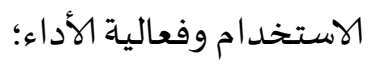
> من الواجب على المؤسسات التعليمية كذلك إعادة صياغة مناهجية الواهيا التعليمية

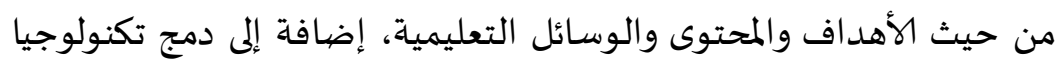

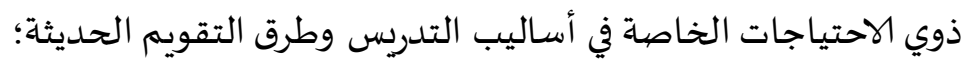

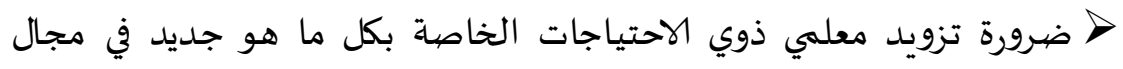

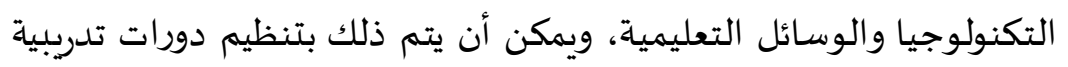
وورش عمل للمعلمين.

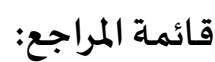

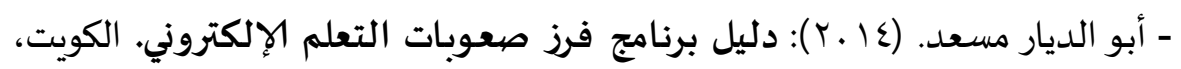

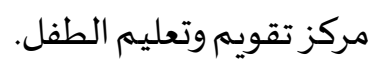
- أبو العز سلامة عادل، وزملاؤه. (9 . ب ): طرائق التدريس العامة، عمان، دار الثقافة. 
- أبولوم أمجد. (Y.Y. أ.Y): دور التكنولوجيا في تعلم الطلاب ذوي صعوبات التعلم.

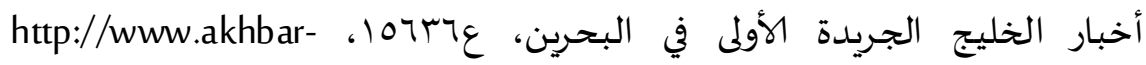

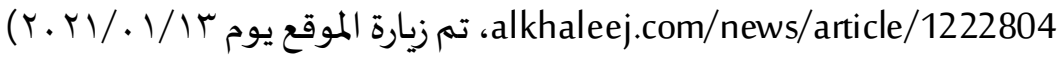

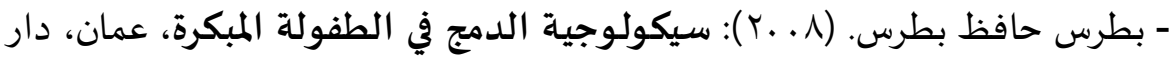
المسيرة.

- بني هاني وليد عبد. (10 ـ †): أنشطة وتطبيقات في صعوبات التعلم. عمان، دار عالم الثقافة. - جدوع عصام. (Y (Y)): صعوبات التعلم. عمان، دار اليازوري العلمية للنشر والتوزع.

- الحيلة محمود محمد. (. ب. ب): تصيميم وإنتاج الوسـائل التعليمية العلمية. عمان، دار المسيرة.

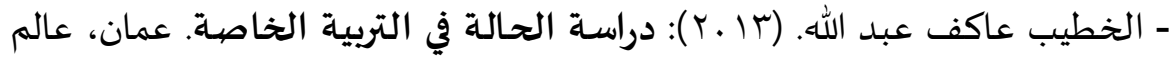
الكتب الحديث. - الوقفي راضي. (Y . . Y): صعوبات التعلم يين النظري والتطبيقي. عمان، منشورات كلية الأميرة ثروت. - مي راضي. - السعود محمد خالد. (9 . ب): تكنولوجيا ووسـائل التعليم وفعاليتها. عمان، مكتبة المجتمع العربي للنشروالتوزيع. - السعيد هلا. (11 ـ إ): الدمج يين جدية التطبيق والواقع. القاهرة، مكتبة الأنجلو المصرية.

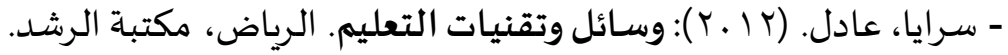

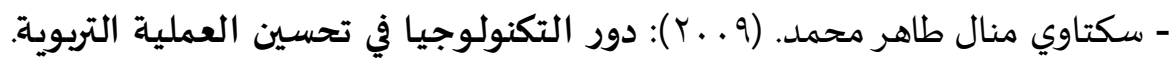
مصر المؤسسة العربية للاستشارات العلمية وتنمية الموارد البشرية.

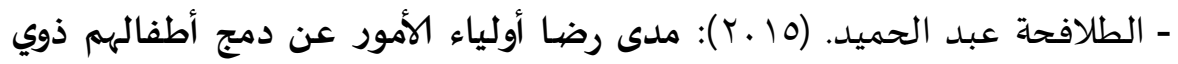

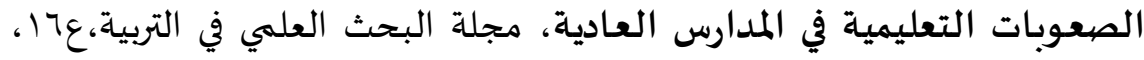
.ร人)-ร79 - عطية عمر مهدي أحمد. (19 ـr): واقع استخدام معلمي التلاميذ ذوي صعوبات

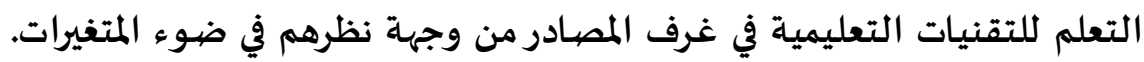


التكنولوجيا التعليمية ودورها في الدمج الأكاديمي للتلاميذ ذوي صعوبات التعلم

مجلة التربية (الأزهر)، مجلة محكمة للبحوث التربوية والنفسية والاجتماعية،

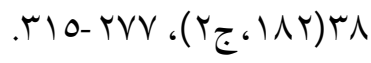

- على أحمد سيد مصطفى، عبد الله عبد الظاهر. (با ـr): التدخل المبكر وإستراتيجيات الدمج. الرياض، د دار الزهراء.

- غنيمات موسى محمد. (0 إب): صعوبات التعلم واقع وأفاق. عمان، دار المعتز. - الفاربي عبد اللطيف وآخرون. (ع991): معجم علوم التربية (مصطلحات البيداغوجيا والديداكتيك). المغرب، دار الخطابي.

- فرماوي أحمد محمود. (T . . †): دور التكنولوجيا في تعليم الكتابة للطلاب ذوي صعوبات التعلم، أطفال الخليج، ذوي الاحتياجات الخاصة، المكتبة الإلكترونية ،

- مثال عبد الله غني. (·. (Y): صعوبات التعلم لدى الأطفال. دراسات تربوياة، $.177-1 \leqslant r_{0}(1.) \mu$

- محمد النوبي محمد علي. (1 (Y): صعوبات التعلم بين المهارات والاضطرابات. عمان، دار صفاء للنشر والتوزع.

- مرزوق سماح عبد الفتاح. (. ـ ؟ ): تكنولوجيا التعليم ذوي الاحتياجات الخاصية. عمان، دار المسيرة للنشروالتوزع.

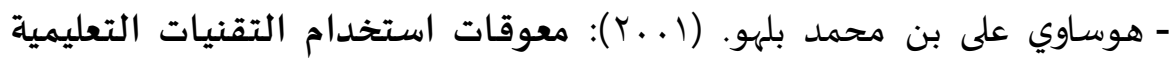
الخاصية في تدرس التلاميذ المتخلفين عقليا كما يدركها معلمي التربية الفكرية لمدينة الرياض. المؤتمر العلمي الأول، جامعة بنمان. - يحيى خوله أحمد. (7 . . ب): البرامج التربوية للأفراد ذوي الاحتياجات الخاصية. عمان، دار المسيرة للنشروالتوزع. 